\title{
Polymorphisms in CYP11B2 and CYP11B1 genes associated with primary hyperaldosteronism
}

\author{
Guo-xi Zhang ${ }^{1,2,6}$, Bao-jun Wang ${ }^{1,6}$, Jin-zhi Ouyang ${ }^{3,6}, \mathrm{Xi-yuan}$ Deng ${ }^{4}$, Xin $\mathrm{Ma}^{1}$, Hong-zhao $\mathrm{Li}^{1}$, Zhun $\mathrm{Wu}^{5}$,
} Shuang-lin $\mathrm{Liu}^{5}$, Hua $\mathrm{Xu}^{5}$ and $\mathrm{Xu} \mathrm{Zhang}^{1}$

Several frequent polymorphisms in the CYP11B2 gene are suggested to be associated with essential hypertension and aldosterone secretion. In this study, we investigated the association of polymorphisms in CYP11B2 and CYP11B1 genes with the risk of primary hyperaldosteronism (PH). Three polymorphisms in the CYP11B2 gene (intron 2 conversion, rs 1799998 and rs4539) and two polymorphisms in the CYP11B1 gene (rs6410 and rs6387) were analyzed in patients with PH and in the normal population. The rs 6410 allelic frequencies in patients with aldosterone-producing adenoma (APA) and idiopathic hyperaldosteronism (IHA) were significantly different from those in controls at $P=1.09 \times 10^{-5}$ and 0.015 , respectively. There was a relative excess of AA homozygotes and AG heterozygotes of the rs6410 allele in the APA group as compared with the control group $\left(P=2.19 \times 10^{-4}\right)$. There were significantly different genotypes, AA and $A G$, of the rs6410 allele between the patients with IHA and the controls only after adjustments for age, gender and body mass index (odds ratio $(O R)=4.06$, $95 \%$ confidence interval (CI) 1.31-12.66; OR $=2.41,95 \% \mathrm{CI} 1.02-5.72$ ). One susceptible haplotype, AAAWT, was identified to be significantly associated with APA $(O R=1.44,95 \% \mathrm{CI} 1.19-1.76)$, and three susceptible haplotypes, AAAWT, AGGWT and AGAWC, were identified to be significantly associated with IHA $(O R=1.55,95 \% \mathrm{Cl} 1.23-1.96 ; 0 R=1.49,95 \% \mathrm{Cl} 1.17-1.89$; $\mathrm{OR}=1.40,95 \% \mathrm{Cl} 1.04-1.88$ ). In contrast, one protective haplotype, GGAWT, showed a significant difference between the patients with APA and controls $(O R=0.73,95 \% \mathrm{Cl} 0.55-0.97)$. Several haplotypes were associated with ARR in both the controls and cases. Our data demonstrated that there was a significant association between polymorphisms in the CYP11B2 and CYP11B1 genes and a genetic predisposition to PH. The association with IHA seemed closer compared with APA. Hypertension Research (2010) 33, 478-484; doi:10.1038/hr.2010.21; published online 26 March 2010

Keywords: CYP11B2; CYP11B1; polymorphism; PH

\section{INTRODUCTION}

Primary hyperaldosteronism (PH) is now recognized as the most common form of secondary hypertension. Cross-sectional and prospective studies reported $\mathrm{PH}$ in $>10 \%$ of hypertensive patients, in both general and specific settings. ${ }^{1}$ The most common clinical subtypes of $\mathrm{PH}$ are aldosterone-producing adenoma (APA) and idiopathic hyperaldosteronism (IHA).

Aldosterone has a key role in APA, and the terminal stages in its synthesis, the synthesis of aldosterone from 11-deoxycorticosterone in the glomerulosa zone, is catalyzed by aldosterone synthase, which is encoded by the CYP11B2 gene. ${ }^{2,3}$ Parallel $11 \beta$-hydroxylation of the 17 hydroxysteroid, which is catalyzed by the enzyme $11 \beta$-hydroxylase encoded by the gene CYP11B1, produces cortisol in the zona fasciculata. ${ }^{4}$ CYP11B2 and CYP11B1 are situated $\sim 40 \mathrm{~kb}$ apart, on chromosome 8 , band 8q24 in human. ${ }^{5}$
Several frequent polymorphisms in CYP11B2 are suggested to have associations with essential hypertension and may influence aldosterone secretion. ${ }^{6-8}$ Recently, several investigators have demonstrated that the $-344 \mathrm{C} / \mathrm{T}$ and the intron 2 conversion variants in CYP11B2 are in strong linkage disequilibrium (LD) with variants in CYP11B1. This can account for the altered $11 \beta$-hydroxylase efficiency and mineralocorticoid synthesis. Such effects may be relevant to the development of low-renin essential hypertension. ${ }^{9,10}$

Inglis et al. ${ }^{11}$ found that the frequencies of the rs1799998T allele and the intron 2 conversion allele in the CYP11B2 gene were markedly higher in Conn's syndrome group than in the normal control group, which demonstrated that the relative genotypes may predispose the tumor to aldosterone production. Tanahashi et al. ${ }^{12}$ considered that a CYP11B2 haplotype, including $-344 \mathrm{~T}$ and K173 in APA, was associated with a higher gene expression than the $-344 \mathrm{C} / \mathrm{R} 173$ haplotype.

\footnotetext{
${ }^{1}$ Department of Urology, Clinical Division of Surgery, Chinese PLA General Hospital, Beijing, PR China; ${ }^{2}$ Department of Urology, First Affiliated Hospital of Gannan Medical University, Ganzhou, PR China; ${ }^{3}$ Department of Endocrinology, Clinical Division of Medicine, Chinese PLA General Hospital, Beijing, PR China; ${ }^{4}$ Department of Urology, Pingdingshan People's Hospital No.1, Pingdingshan, PR China and ${ }^{5}$ Department of Urology, Tongji Hospital/Medical College, Huazhong University of Science and Technology, Wuhan, PR China

6These authors contributed equally to the work.

Correspondence: Professor Xu Zhang, Department of Urology, Clinical Division of Surgery, Chinese PLA General Hospital, No.28, Fu Xing Road, Hai Dian District, Beijing 100853, PR China.

E-mail: xzhang@tjh.tjmu.edu.cn

Received 16 August 2009; revised 9 January 2010; accepted 22 January 2010; published online 26 March 2010
} 
However, in a study of normal subjects and patients with $\mathrm{PH}$ and essential hypertension, rs1799998, rs4539 and intron 2 conversion polymorphisms in the CYP11B2 gene may contribute to the dysregulation of aldosterone synthesis and may lead to susceptibility to IHA but not to APA. ${ }^{13}$

To date, the association between CYP11B2 and CYP11B1 polymorphisms and the development of $\mathrm{PH}$ are still unclear. There has been no report on the association between CYP11B1 polymorphisms and $\mathrm{PH}$. In this study, we aimed to identify polymorphisms in CYP11B2 and CYP11B1 genes that are associated with $\mathrm{PH}$, with the hypothesis that genetic variants in them may contribute to $\mathrm{PH}$.

\section{METHODS}

\section{Subjects}

A total of 179 Chinese Han in-patients with PH, including 134 with APA and 45 with IHA (with at least one dominant adrenal nodule and drug-resistant hypertension), were recruited from Tongji Hospital (Wuhan, China) between February 2002 and December 2007. The diagnosis of PH was a three-step process as previously described. ${ }^{14}$ Briefly, (1) all patients had refractory hypertension, elevated plasma aldosterone concentration (PAC) ( $>17.4 \mathrm{ng}$ per $100 \mathrm{ml}$ ) and an increased ARR ( $>50 \mathrm{ng}$ per $100 \mathrm{ml}$ per $\mathrm{ng} \mathrm{ml}^{-1} \mathrm{~h}^{-1}$ ); (2) all had positive results of subsequent confirmatory testing (intravenous saline loading) $;^{15}$ (3) all patients underwent a computed tomography scan with fine cuts $(2.5-3 \mathrm{~mm})$, and $65 \%$ of the patients accepted adrenal venous sampling (AVS) for differentiating PH subtypes. For AVS, we followed the same criteria as those in Torino, Italy. ${ }^{16}$ Adrenal vein cannulation was considered successful if the adrenal vein/inferior vena cava cortisol gradient was at least 2 . Lateralization was considered when the aldosterone/cortisol ratio from one adrenal was at least four times the ratio from the other adrenal gland. In addition, glucocorticoid remediable aldosteronism was excluded in all patients using a long PCR technique as previously described..$^{14}$ The medications thought not to affect aldosterone and plasma renin activity (PRA) levels, including spironolactone, were withdrawn for at least 4 weeks before the diagnostic tests. All patients underwent unilateral adrenalectomy, and the diagnoses were surgically and histologically strengthened.

A total of 118 ethnically and geographically matched controls were randomly selected from normal individuals of community-based residents. All controls were free of adrenal ailment. The clinical characteristics of the patients and controls are given in Table 1.

Table 1 Clinical characteristics of the study population ${ }^{\text {a }}$

\begin{tabular}{|c|c|c|c|c|}
\hline & \multirow{2}{*}{$\begin{array}{l}\text { Controls } \\
(\mathrm{n}=118)\end{array}$} & \multicolumn{2}{|c|}{ Cases $(\mathrm{n}=179)$} & \multirow[b]{2}{*}{ P-value } \\
\hline & & $A P A(\mathrm{n}=134)$ & $I H A(n=45)$ & \\
\hline Age (years) & $41.5 \pm 1.43$ & $43.2 \pm 1.07$ & $43.6 \pm 1.15$ & 0.327 \\
\hline Gender (M/F) & $61 / 57$ & $61 / 73$ & $22 / 23$ & 0.691 \\
\hline $\mathrm{BMI}\left(\mathrm{kg} \mathrm{m}^{-2}\right)$ & $22.4 \pm 0.31$ & $22.8 \pm 0.39$ & $23.7 \pm 0.44$ & 0.085 \\
\hline SBP (mm Hg) & $110.0 \pm 2.32$ & $172.4 \pm 2.71$ & $168.7 \pm 3.43$ & $<0.001$ \\
\hline DBP (mm Hg) & $76.6 \pm 1.35$ & $106.6 \pm 1.66$ & $107.4 \pm 1.79$ & $<0.001$ \\
\hline $\mathrm{K}\left(\mathrm{mmol} \mathrm{I}^{-1}\right)^{\mathrm{b}}$ & $4.5 \pm 0.05$ & $3.2 \pm 0.07$ & $3.1 \pm 0.05$ & $<0.001$ \\
\hline $\begin{array}{l}\text { PRA (ng ml } l^{-1} \mathrm{~h}^{-1} \text { ) } \\
\text { (supine) }^{\mathrm{b}}\end{array}$ & $0.56 \pm 0.01$ & $0.04 \pm 0.01$ & 0.0 & $<0.001$ \\
\hline $\begin{array}{l}\text { PAC (ng per } 100 \mathrm{ml} \text { ) } \\
\text { (supine) }^{\mathrm{b}}\end{array}$ & $10.15 \pm 3.67$ & $22.40 \pm 1.09$ & $23.30 \pm 1.28$ & $<0.001$ \\
\hline $\begin{array}{l}\text { ARR (ng per } 100 \mathrm{ml} \\
\left.\text { per } \mathrm{ng} \mathrm{ml}^{-1} \mathrm{~h}^{-1}\right)^{\mathrm{b}}\end{array}$ & $23.98 \pm 1.56$ & $532.01 \pm 25.65$ & $564.91 \pm 57.60$ & $<0.001$ \\
\hline \multicolumn{5}{|c|}{$\begin{array}{l}\text { Abbreviations: APA, aldosterone-producing adenoma; BMI, body mass index; DBP, diastolic } \\
\text { blood pressure; F, female; IHA, idiopathic hyperaldosteronism; K, potassium; M, male; PAC, } \\
\text { plasma aldosterone concentration; PRA, plasma renin activity; SBP, systolic blood pressure. } \\
\text { aData were expressed as mean } \pm \text { s.e. or } n \text { for variables. } \\
\text { bThe normal range of serum potassium (K+) was } 3.5-5.5 \mathrm{mmol} \mathrm{I}^{-1}, 5.9-17.4 \mathrm{ng} \text { per } 100 \mathrm{ml} \text { for } \\
\text { PAC (supine), } 0.05-0.79 \mathrm{ng} \mathrm{ml}^{-1} \mathrm{~h}^{-1} \text { for PRA (supine) and } \leqslant 50 \mathrm{ng} \text { per } 100 \mathrm{ml} \text { per } \mathrm{ngl}^{-1} \mathrm{~h}^{-1} \\
\text { for ARR. }\end{array}$} \\
\hline
\end{tabular}

The study was approved by the Committee of Ethics at Tongji Medical College, Huazhong University of Science and Technology, and all subjects gave informed consents.

\section{Genotyping}

Among the participants, 119 cases (88 with APA and 31 with IHA) provided frozen tissues, 60 cases (46 with APA and 14 with IHA) provided paraffinembedded tissues and 118 controls provided peripheral blood samples for genotyping. DNA was extracted from the tissues and peripheral blood using DNeasy Blood and Tissue Kit (Cat. No. 69504; Qiagen, Hilden, Germany), as instructed. It was maintained at $-20^{\circ} \mathrm{C}$.

For the CYP11B2 and CYP11B1 genes, four single-nucleotide polymorphisms (SNPs) of minor allele frequency $\geqslant 0.05$ were selected in public databases (http://ncbi.nlm.nih.gov/SNP/ and http://www.hapmap.org/) for study. This is based on the evidence suggesting functional relevance or reports of association with hypertension. ${ }^{1-13,17}$ Two SNPs span the CYP11B2 gene: rs1799998 in the promoter region (also known in previous publications as C-344T or SF-1) and rs4539 in the third exon (also known as A2718G or K173R). Two SNPs span the CYP11B1 gene: rs 6410 (G225A) in the first exon and rs6387 (A2803G) in the third intron. We also typed the biallelic intron 2 conversion polymorphism in the CYP11B2 gene. This variant exists in two alternate forms, either the wild type $(\mathrm{W})$ or the conversion $(\mathrm{C})$, in which part of intron 2 is replaced by the corresponding intron of the adjacent CYP11B1 gene ${ }^{18}$ (Figure 1).

Analysis of the intron 2 conversion polymorphism was performed using two separate PCRs. One amplifies the wide-type gene, and the other amplifies the conversion gene. The forward and reverse primers were respectively as follows: $5^{\prime}$-TGGAGAAAAGCCCTACCCTGT- $3^{\prime}$ and $5^{\prime}$-AGGAACCTCTGCACGGCC- $3^{\prime}$ for the wide-type gene and $5^{\prime}$-CAGAAAATCCCTCCCCCCTA- $3^{\prime}$ and $5^{\prime}$-AGG AACCTCTGCACGGCC-3' for the conversion gene. Each $25 \mu \mathrm{l}$ assay mix contained $12.5 \mu \mathrm{l} 2 \times$ Taq PCR MasterMix (Tiangen, Beijing, China), $2 \mu \mathrm{l}$ mixture of forward and reverse primers and $1 \mu \mathrm{g}$ DNA. The reaction was subjected to 31 cycles at $95{ }^{\circ} \mathrm{C}$ for $30 \mathrm{~s}$, at $64{ }^{\circ} \mathrm{C}$ for $25 \mathrm{~s}$ and at $72{ }^{\circ} \mathrm{C}$ for $30 \mathrm{~s}$, followed by a final extension at $72^{\circ} \mathrm{C}$ for $10 \mathrm{~min}$. The size of the amplicon in each reaction was $\sim 418 \mathrm{bp}$. The SNPs in the CYP11B2 and CYP11B1 genes were analyzed using TaqMan probes. Primers and probes were designed and synthesized by Applied Biosystems (Foster City, CA, USA). All samples were genotyped using the Stratagene Mx3000P instrument (Applied Biosystems) as instructed. Each assay was carried out using $20 \mathrm{ng}$ DNA in a $20 \mu \mathrm{l}$ reaction containing a TaqMan universal PCR master mix (Applied Biosystems), forward and reverse primers, and FAM- and VIC-labeled probes designed and synthesized by Applied Biosystems. Allelic discrimination was measured automatically by Mxpro 6.0, and the genotype was determined. A random sample of $10 \%$ of the cases and controls was typed twice by different methods (independent PCRs or DNA sequencing) to confirm that the genotyping and reproducibility were $100 \%$.

\section{Statistical analysis}

Demographic data were expressed as mean \pm s.e. or $n$ for variables and were performed with SPSS 13.0 (SPSS Inc, Chicago, IL, USA) for Windows. The differences between groups were assessed using one-way analysis of variance and the $\chi^{2}$-test. $P<0.05$ was considered statistically significant.

The Hardy-Weinberg equilibrium and the difference in genotype frequencies between cases and controls of each polymorphism were determined by SNPassoc 1.5-3 with Bonferroni correction for R 2.7.0 statistics program (freely obtained by http://www.r-project.org/). In addition, multivariable unconditional logistic regression was used to estimate odds ratio (OR) and 95\% confidence interval (CI) after adjustments for gender, age and body mass index (BMI) by SNPassoc. With the help of Haploview 4.0 for Windows, pairwise LD was estimated by $D^{\prime}$, the difference in allelic frequencies between the case and control groups of each polymorphism was determined and allelic permutation test with 10000 times was performed. The haplotype frequencies for various polymorphism combinations were estimated by Haplo.stats 1.3.8 for the R 2.7.0 statistics program. The differences in haplotype frequency profiles between the case and control groups were determined, and haplotype-based hypothesis tests of generalized linear models were conducted using the software haplo.stats with Bonferroni correction. The association between CYP11B2-CYP11B1 genotypes/haplotypes and ARR was 


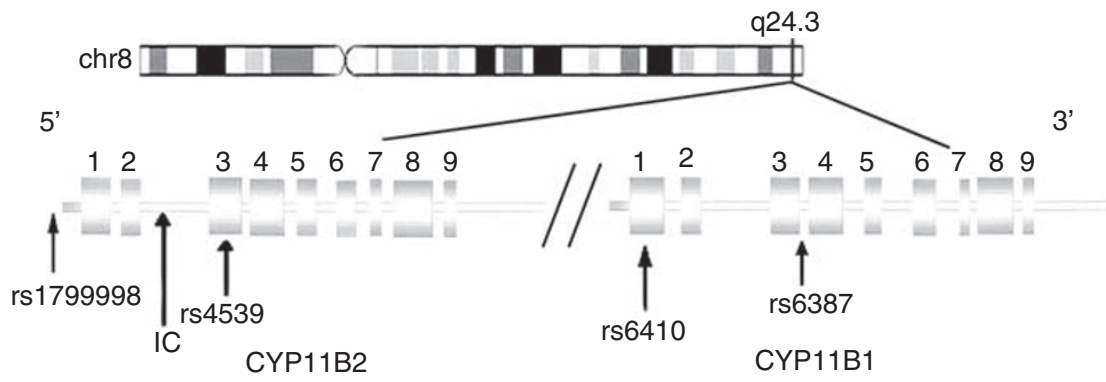

Figure 1 Schematic representation illustrating the five typed polymorphisms in the CYP11B2 and CYP11B1 genes (locations in the chromosome are shown). Exons are numbered and names for the polymorphisms are given below the arrow. IC represented CYP11B2 intron 2 conversion.

Table 2 Allele frequencies in APA, IHA and the control group

\begin{tabular}{|c|c|c|c|c|c|c|c|c|}
\hline \multirow{3}{*}{$\begin{array}{l}\begin{array}{l}\text { Variation } \\
\text { position }\end{array} \\
\text { rs6387 }\end{array}$} & \multicolumn{6}{|c|}{ Allele frequencies } & \multicolumn{2}{|c|}{ P-value } \\
\hline & \multicolumn{2}{|c|}{$\begin{array}{l}\text { Controls } \\
(n=118)\end{array}$} & \multicolumn{2}{|c|}{$\begin{array}{c}A P A \\
(\mathrm{n}=134)\end{array}$} & \multicolumn{2}{|c|}{$\begin{array}{c}1 H A \\
(n=45)\end{array}$} & \multirow{2}{*}{$\begin{array}{r}A P A^{\mathrm{a}} \\
0.462\end{array}$} & \multirow{2}{*}{$\begin{array}{l}1 H A^{\mathrm{a}} \\
0.935\end{array}$} \\
\hline & A & G & A & G & A & G & & \\
\hline & 0.73 & 0.27 & 0.76 & 0.24 & 0.74 & 0.26 & & \\
\hline \multirow[t]{2}{*}{ rs6410 } & A & G & A & G & A & G & $1.09 \times 10^{-5}$ & 0.015 \\
\hline & 0.24 & 0.76 & 0.42 & 0.58 & 0.37 & 0.63 & & \\
\hline \multirow[t]{2}{*}{ rs4539 } & A & G & A & G & A & G & 0.499 & 0.430 \\
\hline & 0.71 & 0.29 & 0.74 & 0.26 & 0.76 & 0.24 & & \\
\hline \multirow[t]{2}{*}{ IC } & W & C & W & C & W & C & 0.546 & 0.168 \\
\hline & 0.79 & 0.21 & 0.81 & 0.19 & 0.85 & 0.15 & & \\
\hline \multirow[t]{2}{*}{ rs1799998 } & C & $\mathrm{T}$ & C & $\mathrm{T}$ & C & $\mathrm{T}$ & 0.335 & 0.160 \\
\hline & 0.29 & 0.71 & 0.25 & 0.75 & 0.21 & 0.79 & & \\
\hline
\end{tabular}

Abbreviations: APA, aldosterone-producing adenoma; C, conversion; IHA, idiopathic hyperaldosteronism; IC, intron 2 conversion; W, wide type.

aAPA and IHA vs. controls.

analyzed by SNPassoc and haplo.stats. $P<0.05$ or $95 \%$ CI of OR not including 1.0 implied statistical significance, and all statistical tests were two sided.

\section{RESULTS}

All selected diallelic polymorphisms in the case-control populations were successfully genotyped. The allele and genotype frequencies for cases and controls are shown in Tables 2 and 3. The distribution of genotypes was in accordance with the Hardy-Weinberg equilibrium in each group $(P>0.05)$. The degrees of pairwise LD among all selected variants were estimated by the standardized disequilibrium coefficient $D^{\prime}$ (Figure 2). It was shown that these five variants were in different strengths of LD, with the rs6410 and rs6387 polymorphisms in the tightest $\mathrm{LD}\left(D^{\prime} 0.66\right)$, and rs4539 and intron 2 conversion having the weakest $\mathrm{LD}\left(D^{\prime}\right.$ 0.06) in the control subjects.

\section{CYP11B2-CYP11B1 genotypes in relation to $\mathrm{PH}$}

Univariate allelic frequency analyses revealed that only rs6410 was significantly associated with APA and IHA at $P=1.09 \times 10^{-5}$ and 0.015 , respectively (Table 2$)$. Further, this SNP was still significantly associated with APA after 10000 times permutation $\left(P=1 \times 10^{-4}\right)$. There was a statistically significant difference in APA even after applying Bonferroni correction to this study $\left(P=5 \times 10^{-4}\right)$. There was a relative excess of AA homozygotes and AG heterozygotes of the rs6410 allele in the APA group as compared with the control group (Table 3). Multivariate unconditional logistic regression analyses demonstrated that this significant association between rs6410 and APA was consistent even when there were adjustments for age, gender and BMI (Table 3). Simultaneously, a marginal difference was found in the rs6410 genotype frequencies between the control group and the IHA group, which became statistically significant after adjustments for age, gender and BMI (Table 3). In contrast, there was no significant difference in rs6387, rs4539, intron 2 conversion and rs 1799998 between the control group and the APA or IHA group.

\section{CYP11B2-CYP11B1 haplotypes in relation to APA}

The interactions of multiple variants within a haplotype may have an impact on the biological phenotype. ${ }^{19}$ We therefore proceeded to analyze the effect of these five polymorphisms in CYP11B2 and CYP11B1 genes on the risk of APA in the context of haplotypes. Haplotype analysis for the five polymorphisms was implemented using haplo.stats software. Haplotypes with an estimated frequency of $>3 \%$ in patients with APA or the controls are shown in Table 4. A highly significant difference was observed in the haplotype frequencies between the control subjects and the patients with APA (Globalstat $=31.95$, degrees of freedom $=9, P=0.0002$ ). Individually, a susceptible haplotype, AAAWT, was identified to be significantly associated with APA with empirical $P$-values of $5.0 \times 10^{-5}$ (Table 4 ). In contrast, one protective haplotype, GGAWT, showed a significant difference between patients with APA and the controls (empirical $P=1.0 \times 10^{-4}$ ). Importantly, all the above results of each haplotype remained significant even after Bonferroni correction $\left(P=4.5 \times 10^{-4}\right.$ and $9.0 \times 10^{-4}$, respectively). Comparisons between one haplotype $v s$. all others in both the cases and controls were made to determine the possible specific disease-predisposing haplotypes in patients with APA. The haplotype chosen for the reference in the model was AGAWT, which has the highest frequency. One susceptible haplotype, AAAWT, displayed a significantly increased risk for APA (OR 15.89, 95\% CI 2.06122.89), which was consistent even when there were adjustments for age, gender and BMI (OR 1.44, 95\% CI 1.19-1.76). In contrast, a protective haplotype, GGAWT, exhibited significantly decreased effect on APA (OR 0.08, 95\% CI 0.01-0.69), and there was a significant difference even after adjustments for age, gender and BMI (OR 0.73, 95\% CI 0.55-0.97). In addition, two susceptible haplotypes, GAACT and AGGWT, were found with a marginal significance in the difference between the control group and the APA group after adjustments for age, gender and BMI (OR 1.28, 95\% CI 0.97-1.71 and OR 1.23, 95\% CI 0.99-1.54, respectively).

\section{CYP11B2-CYP11B1 haplotypes in relation to IHA}

Haplotypes with an estimated frequency of $>3 \%$ in patients with IHA or the controls are shown in Table 5. A significant difference was found in the haplotype frequencies between the control subjects and 
Table 3 The genotype and variation frequencies of DNA polymorphisms in CYP11B2 and CYP11B1 genes

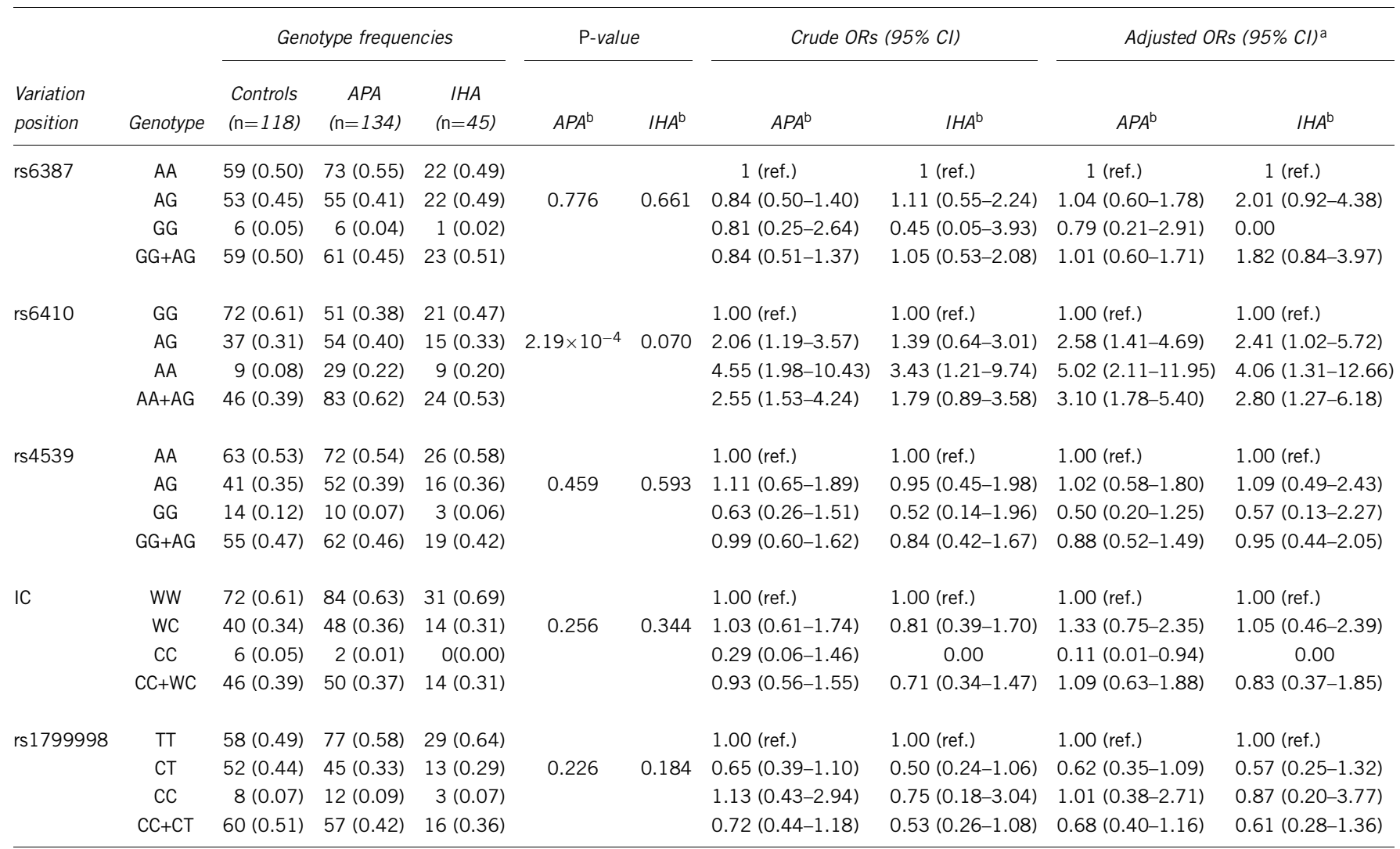

Abbreviations: APA, aldosterone-producing adenoma; C, conversion; Cl, confidence interval; IHA, idiopathic hyperaldosteronism; IC, intron 2 conversion; OR, odds ratio; ref., reference; W, wide type. ${ }^{a}$ Adjusted OR $(95 \% \mathrm{Cl})$ were computed with multivariate unconditional logistic regression analysis after adjustment in age, gender and body mass index.

${ }^{\mathrm{b}} \mathrm{APA}$ and IHA vs. controls.

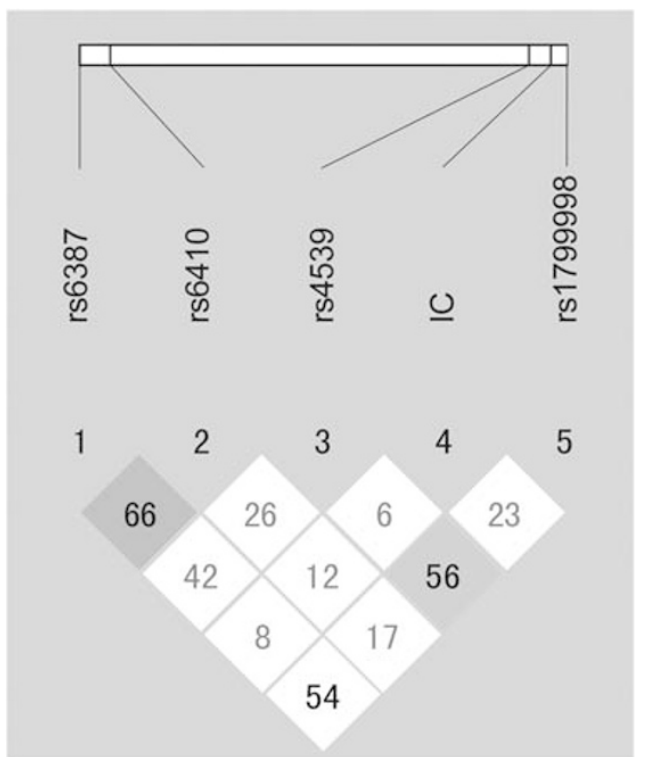

Figure 2 LD structure of the locus in CYP11B2 and CYP11B1 genes. Estimated values of $D^{\prime}$, generated by Haploview 4.0 from the genotypes of 118 controls, are in the grids. IC represented CYP11B2 intron 2 conversion.

the patients with IHA (Global-stat $=19.06$, degrees of freedom $=9$, $P=0.025)$. Interestingly, a haplotype, AAAWT, was also identified to be significantly associated with IHA $\left(P=2 \times 10^{-3}\right)$. There was a significant difference even after Bonferroni correction $(P=0.018)$. The most frequent haplotype, AGAWT, was chosen as the reference when comparisons between one haplotype vs. all others in patients with IHA and the controls were made. The subjects carrying a susceptible haplotype, AAAWT, showed a significant increased risk for IHA (OR 4.99, 95\% CI 1.29-19.35), which was consistent even when there were adjustments for age, gender and BMI (OR 1.55, 95\% CI 1.23-1.96). Moreover, the risk conferred by the haplotype, AAAWT, on IHA was higher as compared with APA (OR 1.55 vs. OR 1.44). A susceptible haplotype, AGGWT, was found with a marginal significance in the difference between the control group and the IHA group (OR 2.92, 95\% CI 0.82-10.45), and had a significantly increased risk after adjustments for age, gender and BMI (OR 1.49, 95\% CI 1.17-1.89). Another susceptible haplotype, AGAWC, was found to have a significantly increased risk only after adjustments for age, gender and BMI (OR 1.40, 95\% CI 1.04-1.88).

\section{CYP11B2-CYP11B1 genotypes/haplotypes in relation to ARR}

None of the CYP11B2-CYP11B1 genotypes was found to be associated with ARR. However, two haplotypes, AAAWT and GAAWT, were associated with ARR when there were adjustments for age, gender and BMI in the control group (coefficient $=65.09, \quad P<0.001$ and coefficient $=18.86, P<0.001$, respectively). In the APA group, three haplotypes, AAAWT, AGGWC and GAACT, were also found associated with ARR when there were adjustments for age, gender and BMI (coefficient $=40.17, P<0.001$; coefficient $=56.81, P<0.001$ and coefficient $=-24.36, P<0.001$, respectively). Likewise, two haplotypes, 
Table 4 Assessment of association between CYP11B2-CYP11B1 haplotypes and APA

\begin{tabular}{|c|c|c|c|c|c|c|c|}
\hline \multirow[b]{2}{*}{ Haplotypes $^{\mathrm{a}}$} & \multicolumn{2}{|c|}{ Frequencies of haplotype } & \multirow[b]{2}{*}{$\begin{array}{l}\text { Empirical } \\
\text { P-value }\end{array}$} & \multirow[b]{2}{*}{$\begin{array}{l}\text { Crude ORs } \\
(95 \% \mathrm{Cl})^{\mathrm{c}}\end{array}$} & \multirow[b]{2}{*}{ Crude P-value ${ }^{\mathrm{C}}$} & \multirow[b]{2}{*}{$\begin{array}{c}\text { Adjusted ORs } \\
(95 \% \mathrm{Cl})^{\mathrm{d}}\end{array}$} & \multirow[b]{2}{*}{$\begin{array}{l}\text { Adjusted } \\
\text { P-value }\end{array}$} \\
\hline & $\begin{array}{l}\text { Control } \\
(\mathrm{n}=118)\end{array}$ & $\begin{array}{c}A P A \\
(\mathrm{n}=134)\end{array}$ & & & & & \\
\hline AGAWT & $36(0.31)$ & $35(0.26)$ & 0.402 & Reference & & Reference & \\
\hline AGGWC & $18(0.15)$ & $16(0.12)$ & 0.184 & $0.80(0.41-1.57)$ & 0.436 & $0.93(0.80-1.09)$ & 0.375 \\
\hline GAAWT & $14(0.12)$ & $15(0.11)$ & 0.281 & $0.94(0.45-1.96)$ & 0.971 & $1.07(0.91-1.26)$ & 0.414 \\
\hline GAACT & $3(0.03)$ & $9(0.07)$ & 0.426 & $2.29(0.66-7.94)$ & 0.246 & $1.28(0.97-1.71)$ & 0.088 \\
\hline AGGWT & $3(0.03)$ & $9(0.07)$ & 0.125 & $2.56(0.78-8.34)$ & 0.089 & $1.23(0.99-1.54)$ & 0.067 \\
\hline AAAWT & $1(0.01)$ & $15(0.11)$ & $5.0 \times 10^{-5}$ & $15.89(2.06-122.89)$ & 0.0004 & $1.44(1.19-1.76)$ & 0.0003 \\
\hline AGAWC & $5(0.04)$ & $6(0.04)$ & 0.776 & $1.11(0.43-2.87)$ & 0.860 & $1.05(0.84-1.31)$ & 0.686 \\
\hline
\end{tabular}

Abbreviations: APA, aldosterone-producing adenoma; $\mathrm{Cl}$, confidence interval; d.f., degrees of freedom; OR, odds ratio.

aThe sequence of the variants in the haplotypes rs6387, rs6410, rs4539, intron 2 conversion and rs 1799998.

bEmpirical $P$-value based on 10000 permutations.

comparisons were made between one haplotype (reference) vs. all others in the cases and controls.

${ }^{\mathrm{d}}$ Adjusted for age, gender and body mass index.

Table 5 Assessment of association between CYP11B2-CYP11B1 haplotypes and IHA

\begin{tabular}{|c|c|c|c|c|c|c|c|}
\hline \multirow[b]{2}{*}{ Haplotypes $^{\mathrm{a}}$} & \multicolumn{2}{|c|}{ Frequencies of haplotype } & \multirow[b]{2}{*}{$\begin{array}{l}\text { Empirical } \\
\text { P-value }\end{array}$} & \multirow[b]{2}{*}{$\begin{array}{l}\text { Crude ORs } \\
(95 \% \mathrm{Cl})^{\mathrm{c}}\end{array}$} & \multirow[b]{2}{*}{$\begin{array}{l}\text { Crude } \\
\text { P-value }\end{array}$} & \multirow[b]{2}{*}{$\begin{array}{c}\text { Adjusted } \\
\text { ORs }(95 \% \text { CI) }\end{array}$} & \multirow[b]{2}{*}{$\begin{array}{l}\text { Adjusted } \\
P \text {-value }\end{array}$} \\
\hline & Control $(\mathrm{n}=118)$ & IHA $(\mathrm{n}=45)$ & & & & & \\
\hline AGAWT & $36(0.31)$ & $16(0.35)$ & 0.944 & Reference & & Reference & \\
\hline AGGWC & $18(0.15)$ & $3(0.07)$ & 0.115 & $0.58(0.23-1.46)$ & 0.270 & $0.96(0.82-1.12)$ & 0.580 \\
\hline GAAWT & $14(0.12)$ & $5(0.11)$ & 0.381 & $1.33(0.54-3.30)$ & 0.477 & $1.12(0.93-1.35)$ & 0.218 \\
\hline AGGWT & $3(0.03)$ & $5(0.11)$ & 0.053 & $2.92(0.82-10.45)$ & 0.054 & $1.49(1.17-1.89)$ & 0.001 \\
\hline AAAWT & $1(0.01)$ & $5(0.11)$ & 0.002 & $4.99(1.29-19.35)$ & 0.004 & $1.55(1.23-1.96)$ & 0.0003 \\
\hline AGAWC & $5(0.04)$ & $1(0.02)$ & 0.908 & $1.39(0.26-7.43)$ & 0.664 & $1.40(1.04-1.88)$ & 0.027 \\
\hline \multirow[t]{2}{*}{ GAACT } & $3(0.03)$ & $2(0.03)$ & 0.831 & $0.84(0.13-5.29)$ & 0.892 & $0.87(0.69-1.08)$ & 0.414 \\
\hline & \multicolumn{3}{|c|}{ Global-stat $=19.06$, d.f. $=9, P=0.025$} & & & & \\
\hline
\end{tabular}

Abbreviations: $\mathrm{Cl}$, confidence interval; d.f., degrees of freedom; IHA, idiopathic hyperaldosteronism; OR, odds ratio.

aThe sequence of the variants in the haplotypes rs6387, rs6410, rs4539, intron 2 conversion and rs 1799998.

bEmpirical $P$-value based on 10000 permutations.

'Comparisons were made between one haplotype (reference) vs. all others in the cases and controls.

${ }^{\mathrm{d}}$ Adjusted for age, gender and body mass index.

AAAWT and GAAWT, were associated with ARR when there were adjustments for age, gender and BMI in IHA group (coefficient $=272.16, \quad P<0.001$ and coefficient=237.1, $\quad P<0.001$, respectively).

\section{DISCUSSION}

No satisfactory explanation is yet available for the initiation of growth of PH. In this study, five polymorphisms spanning the CYP11B1 and CYP11B2 locus were genotyped. Among them, the rs6410 polymorphism showed a significant association with APA and IHA in the Chinese Han population, which was similar to Keavney's findings on the association between the rs6410 polymorphism and 11-deoxycortisol urinary metabolite excretion in the Caucasian population. ${ }^{20}$ To our knowledge, this is the first report wherein a significant association of the polymorphisms of the CYP11B1 gene with $\mathrm{PH}$ was found. The present results further provided some useful information for the investigation of the association between the polymorphisms of the CYP11B2 and CYP11B1 genes and PH in the Chinese Han population.
To our knowledge, the CYP11B1 gene is responsible for the final step in cortisol synthesis, not for aldosterone synthesis. Furthermore, it is unlikely that the rs6410 polymorphism in CYP11B1 gene directly influences the phenotype because it involves a change from $G$ to $A$ at codon 75 , which has no consequences for the amino-acid sequence of the final protein due to the same leucine encoded in both cases. There may be two possible mechanisms by which this polymorphism can influence the trait. One exists in the LD between the rs6410 variant in CYP11B1 and the undiscovered causative variant(s) in CYP11B2. Another may be that the rs6410 variant is in $L D$ with causal variant(s) in CYP11B1 itself. This leads to the reduced $11 \beta$-hydroxylase efficiency, then mildly activates the pituitary-adrenal axis and finally influences the aldosterone production. As a result, hypertension or even $\mathrm{PH}$ may occur. Our hypothesis is consistent with some previous findings. Connell and coworkers ${ }^{9,10}$ found that reduced $11 \beta$-hydroxylase efficiency and increased aldosterone production are associated with genetic variations (for example, rs1799998, intron 2 conversion, rs6410, $-1859 \mathrm{G} / \mathrm{T}$ and $-1889 \mathrm{~A} / \mathrm{G})$ of CYP11B2 and CYP11B1 genes 
in hypertension patients and normal objects. They also observed that variants in CYP11B2 and CYP11B1 are in strong $\mathrm{LD}$ and associated with the chronic upregulation of hypothalamic-pituitary-adrenal axis activity. ${ }^{20,21}$ Taken together, these findings suggest that reduced $11 \beta$ hydroxylase efficiency in genetically susceptible individuals mildly activates the pituitary-adrenal axis by a slight and lifelong increase in adrenocorticotropic hormone and influences the aldosterone production, which may lead to the development of hypertension within the general population. ${ }^{21}$ Moreover, these results were confirmed by others. ${ }^{17,22}$

In this study, no correlation of APA and IHA with rs6387, rs4539, intron 2 conversion and rs1799998 polymorphisms in the CYP11B2 and CYP11B1 genes was found, which does not agree with previous reports. ${ }^{11,13}$ The allele and genotype frequencies as well as the CYP11B2-CYP11B1 haplotypes identified also differed from the ones previously found by Ganapathipillai et al. ${ }^{17}$ In addition, in contrast to those previous studies, we only observed mild or weak, but not strong LD among rs6410, rs4539, intron 2 conversion and rs1799998 alleles. In some previous hypertension studies, the rs1799998 polymorphism is not associated with increased aldosterone and increased blood pressure..$^{23-25}$ Maybe, the different groups with different ethnic backgrounds could account for the differences, but further research is needed to verify this.

Haplotype analysis can overcome the loss of information attributable to biallelic variants, which could make an existing association clearer and more credible. ${ }^{26}$ To further supplement our understanding of the contributions of these genetic variants to APA and IHA, fivelocus haplotypes were constructed, and their distribution was studied in the patients and control populations. AAAWT was identified as the susceptible haplotype, whereas GGAWT was identified as the protective haplotype in patients with APA. In the IHA group, the risk haplotype, AAAWT, was consistent with that in the APA group, but the risk was higher than that of APA. This demonstrated that there are both differences and similarities in the association between polymorphisms in CYP11B2 and CYP11B1 genes and APA and IHA. In the function study, ARR was found to increase in the carriers of the susceptible haplotype, AAAWT, not only in the controls but also in the cases, suggesting a functional significance. Ganapathipillai et al. ${ }^{17}$ also considered that the haplotypes of CYP11B2 and CYP11B1 genes tended to associate with the ARR, as well as predicted the urinary excretion ratio of THS/(THE $+\mathrm{THF}+5 \alpha \mathrm{THF})$, a marker for $11 \beta$ hydroxylase activity. Furthermore, the coefficient of association of haplotype, AAAWT, with ARR in the IHA group was more than that in the APA group (272.16 vs. 40.17). This demonstrated that the effect of the polymorphisms in CYP11B2 and CYP11B1 genes on IHA might be more than that on APA. In other words, the haplotypes analysis suggested that the polymorphisms in CYP11B2 and CYP11B1 genes seemed more closely associated with IHA than APA.

However, there are also some limitations in our study. First, the patients with APA and IHA were recruited from in-patients subjected to unilateral adrenalectomy, which was not completely free from some bias in the selection of study subjects. Further study in a typical population is useful to show the precise association between the polymorphisms in CYP11B2 and CYP11B1 genes and PH. Second, we could not obtain enough information on some environmental exposure factors, such as smoking and drinking status and occupational history in both case and control groups, which may make our results biased. Third, larger samples from a normal population and patients with APA and IHA will be needed in further studies.

In conclusion, our study results reveal a highly significant association between genetic variations in CYP11B2 and CYP11B1 genes and a genetic predisposition to $\mathrm{PH}$. Although we cannot conclude with confidence that the rs6410 variant is a causal polymorphism for $\mathrm{PH}$, significant global and haplotype specific $P$-values support the potential role of CYP11B2 and CYP11B1 genes in the genetic etiology of PH. Moreover, the polymorphisms in CYP11B2 and CYP11B1 genes seemed more closely associated with IHA than APA. Additional research, especially involving more polymorphisms, typical objects, more environmental exposure factors and other study designs, is warranted to further explore the etiological relevance of polymorphisms in CYP11B2 and CYP11B1 genes for APA and IHA.

\section{CONFLICT OF INTEREST}

The authors declare no conflict of interest.

\section{ACKNOWLEDGEMENTS}

This work was supported by the National Natural Science Funds for Distinguished Young Scholar, People's Republic of China (No. 30725040).

1 Funder JW, Carey RM, Fardella C, Gomez-Sanchez CE, Mantero F, Stowasser M, Young Jr WF, Montori VM. Case detection, diagnosis, and treatment of patients with primary aldosteronism: An endocrine society clinical practice guideline. J Clin Endocrinol Metab 2008; 93: 3266-3281.

2 Kawamoto T, Mitsuuchi Y, Toda K, Yokoyama Y, Miyahara K, Miura S, Ohnishi T, Ichikawa Y, Nakao K, Imura H, Ulick S, Shizuta Y. Role of steroid 11 beta-hydroxylase and steroid 18-hydroxylase in the biosynthesis of glucocorticoids and mineralocorticoids in humans. Proc Natl Acad Sci USA 1992; 89: 1458-1462.

3 Curnow KM, Tusie-Luna MT, Pascoe L, Natarajan R, Gu JL, Nadler JL, White PC. The product of the cyp11b2 gene is required for aldosterone biosynthesis in the human adrenal cortex. Mol Endocrinol 1991; 5: 1513-1522.

4 Ferrari P, Bianchetti M, Frey FJ. Juvenile hypertension, the role of genetically altered steroid metabolism. Horm Res 2001; 55: 213-223.

5 Mornet E, Dupont J, Vitek A, White PC. Characterization of two genes encoding human steroid 11 beta-hydroxylase (p-450(11) beta). J Biol Chem 1989; 264: 20961-20967.

6 Davies E, Holloway CD, Ingram MC, Inglis GC, Friel EC, Morrison C, Anderson NH, Fraser R, Connell JM. Aldosterone excretion rate and blood pressure in essential hypertension are related to polymorphic differences in the aldosterone synthase gene cyp11b2. Hypertension 1999; 33: 703-707.

7 Lim PO, Macdonald TM, Holloway C, Friel E, Anderson NH, Dow E, Jung RT, Davies E, Fraser R, Connell JM. Variation at the aldosterone synthase (cyp1 1b2) locus contributes to hypertension in subjects with a raised aldosterone-to-renin ratio. J Clin Endocrinol Metab 2002; 87: 4398-4402.

8 Nicod J, Bruhin D, Auer L, Vogt B, Frey FJ, Ferrari P. A biallelic gene polymorphism of cyp 1 1 b2 predicts increased aldosterone to renin ratio in selected hypertensive patients. J Clin Endocrinol Metab 2003; 88: 2495-2500.

9 Barr M, MacKenzie SM, Friel EC, Holloway CD, Wilkinson DM, Brain NJ, Ingram MC, Fraser R, Brown M, Samani NJ, Caulfield M, Munroe PB, Farrall M, Webster J, Clayton $\mathrm{D}$, Dominiczak AF, Connell JM, Davies E. Polymorphic variation in the 11 beta-hydroxylase gene associates with reduced 11-hydroxylase efficiency. Hypertension 2007; 49: 113-119.

10 Imrie H, Freel M, Mayosi BM, Davies E, Fraser R, Ingram M, Cordell HJ, Farrall M, Avery PJ, Watkins H, Keavney B, Connell JM. Association between aldosterone production and variation in the 11 beta-hydroxylase (cyp11b1) gene. J Clin Endocrinol Metab 2006; 91: 5051-5056.

11 Inglis GC, Plouin PF, Friel EC, Davies E, Fraser R, Connell JM. Polymorphic differences from normal in the aldosterone synthase gene (cyp11b2) in patients with primary hyperaldosteronism and adrenal tumour (Conn's syndrome). Clin Endocrinol (Oxf) 2001; 54: 725-730.

12 Tanahashi H, Mune T, Takahashi Y, Isaji M, Suwa T, Morita H, Yamakita N, Yasuda K, Deguchi T, White PC, Takeda J. Association of lys173arg polymorphism with cyp11b2 expression in normal adrenal glands and aldosterone-producing adenomas. J Clin Endocrinol Metab 2005; 90: 6226-6231.

13 Mulatero P, Schiavone D, Fallo F, Rabbia F, Pilon C, Chiandussi L, Pascoe L, Veglio F. Cyp11b2 gene polymorphisms in idiopathic hyperaldosteronism. Hypertension 2000; 35: 694-698.

14 Mulatero P, Veglio F, Pilon C, Rabbia F, Zocchi C, Limone P, Boscaro M, Sonino N, Fallo F. Diagnosis of glucocorticoid-remediable aldosteronism in primary aldosteronism: aldosterone response to dexamethasone and long polymerase chain reaction for chimeric gene. J Clin Endocrinol Metab 1998; 83: 2573-2575.

15 Holland OB, Brown H, Kuhnert L, Fairchild C, Risk M, Gomez-Sanchez CE. Further evaluation of saline infusion for the diagnosis of primary aldosteronism. Hypertension 1984; 6: 717-723.

16 Mulatero P, Stowasser M, Loh KC, Fardella CE, Gordon RD, Mosso L, Gomez-Sanchez CE, Veglio F, Young Jr WF. Increased diagnosis of primary aldosteronism, including surgically correctable forms, in centers from five continents. J Clin Endocrinol Metab 2004; 89: 1045-1050. 
17 Ganapathipillai S, Laval G, Hoffmann IS, Castejon AM, Nicod J, Dick B, Frey FJ, Frey BM, Cubeddu LX, Ferrari P. Cyp11b2-cyp11b1 haplotypes associated with decreased 11 beta-hydroxylase activity. J Clin Endocrinol Metab 2005; 90: 1220-1225.

18 White P, Slutsker L. Haplotype analysis of cyp11b2. Endocr Res 1995; 21: 437-442.

19 Drysdale CM, McGraw DW, Stack CB, Stephens JC, Judson RS, Nandabalan K, Arnold K, Ruano G, Liggett SB. Complex promoter and coding region beta 2-adrenergic receptor haplotypes alter receptor expression and predict in vivo responsiveness. Proc Natl Acad Sci USA 2000; 97: 10483-10488.

20 Keavney B, Mayosi B, Gaukrodger N, Imrie H, Baker M, Fraser R, Ingram M, Watkins H, Farrall M, Davies E, Connell J. Genetic variation at the locus encompassing 11-beta hydroxylase and aldosterone synthase accounts for heritability in cortisol precursor (11-deoxycortisol) urinary metabolite excretion. J Clin Endocrinol Metab 2005; 90: 1072-1077.

21 Freel EM, Ingram M, Wallace AM, White A, Fraser R, Davies E, Connell JM. Effect of variation in cyp11b1 and cyp11b2 on corticosteroid phenotype and hypothalamicpituitary-adrenal axis activity in hypertensive and normotensive subjects. Clin Endocrinol (Oxf) 2008; 68: 700-706.
22 Kennon B, Ingram MC, Friel EC, Anderson NH, MacKenzie SM, Davies E, Shakerdi L, Wallace AM, Fraser R, Connell JM. Aldosterone synthase gene variation and adrenocortical response to sodium status, angiotensin II and ACTH in normal male subjects. Clin Endocrinol (Oxf) 2004; 61: 174-181.

23 Tsujita Y, Iwai N, Katsuya T, Higaki J, Ogihara T, Tamaki S, Kinoshita M, Mannami T, Ogata J, Baba S. Lack of association between genetic polymorphism of cyp11b2 and hypertension in japanese: the Suita Study. Hypertens Res 2001; 24: 105-109.

24 Pojoga L, Gautier S, Blanc H, Guyene TT, Poirier O, Cambien F, Benetos A. Genetic determination of plasma aldosterone levels in essential hypertension. Am J Hypertens 1998; 11: 856-860.

25 Yamagishi K, Tanigawa T, Cui R, Tabata M, Ikeda A, Yao M, Shimamoto T, Iso H. Aldosterone synthase gene T-344C polymorphism, sodium and blood pressure in a free-living population: a community-based study. Hypertens Res 2007; 30: 497-502.

26 Kumar NN, Benjafield AV, Lin RC, Wang WY, Stowasser M, Morris BJ. Haplotype analysis of aldosterone synthase gene (cyp11b2) polymorphisms shows association with essential hypertension. J Hypertens 2003; 21: 1331-1337. 